\title{
Assessment of diffuse Lewy body disease by 2-[I8F]fluoro-2-deoxy-D-glucose positron emission tomography (FDG PET)
}

\author{
Siroos Mirzaei*1, Peter Knoll1, Horst Koehn ${ }^{1}$ and Thomas Bruecke ${ }^{2}$
}

\author{
Address: ${ }^{1}$ Ludwig Boltzmann Institute of Nuclear Medicine, Wilhelminenspital, Austria and ${ }^{2}$ Department of Neurology, Wilhelminenspital, \\ Vienna, Austria \\ Email: Siroos Mirzaei* - siroos.mirzaei@nuk.wil.magwien.gv.at; Peter Knoll - peter.knoll@nuk.wil.magwien.gv.at; \\ Horst Koehn - horst.koehn@nuk.wil.magwien.gv.at; Thomas Bruecke - thomas.bruecke@neu.wil.magwien.gv.at \\ * Corresponding author
}

Published: 20 February 2003

BMC Nuclear Medicine 2003, 3:1

This article is available from: http://www.biomedcentral.com/I47/-2385/3/I

(c) 2003 Mirzaei et al; licensee BioMed Central Ltd. This is an Open Access article: verbatim copying and redistribution of this article are permitted in all media for any purpose, provided this notice is preserved along with the article's original URL.

\begin{abstract}
Background: Lewy body disease is, after Alzheimer's disease, the second most common cause of senile degenerative dementia with progressive cognitive deterioration, fluctuation of cognitive and motoric functions and psychotic symptoms. It is characterized histologically by the occurrence of Lewy bodies in allocortical, neocortical and subcortical structures. The aim of this study was to measure the cortical glucose metabolism using FDG PET (2-[18F]fluoro-2-deoxy-D-glucose position emission tomography) compared to normal subjects.
\end{abstract}

Patients and Methods: Five patients ( 5 m, mean age 75 y) with clinically suspected diffuse Lewy body disease (DLB) were studied with FDG PET. PET studies of the head were performed with a Siemens ECAT-ART PET-scanner with attenuation correction using I37-Cs point sources.

Results: We found the same distribution pattern of diffuse glucose hypometabolism in the entire cortical region with relative sparing of the primary sensory-motor cortex in all the patients. The few cases reported in the literature so far describe findings similar to ours.

Conclusion: The pattern of diffuse glucose hypometabolism in the entire cortex including the occipital region seems to be a typical feature of DLB that is distinctive from dementia of Alzheimer's disease.

\section{Background}

Dementia with Lewy bodies (DLB) has been established as the second most common senile degenerative dementia after Alzheimer's disease (AD) [1-3]. Lewy bodies, first described in 1912 by F.H. Lewy are distinctive neuronal inclusions that may be seen in several different neurodegenerative processes [4]. Lewy bodies are eosinophilic structures located within the cytoplasm of neurons. They are characteristically circular with a dense protein core sur- rounded by a peripheral halo. They are thought to be the result of altered neurofilament metabolism and/or transport due to neuronal damage and subsequent degeneration, causing an accumulation of altered cytoskeletal elements. $5-10 \%$ of asymptomatic individuals have presumably insignificant numbers of Lewy bodies, usually located in the substantia nigra. [5]. Diagnostic criteria for DLB have been defined to allow clinical diagnosis [3]. Until quite recently, post mortem examination provided the 
definitive diagnosis. However, while these clinical criteria have high specificity (90-97\%), they have low sensitivity $(22-75 \%)$ [6]. The central clinical feature required for a diagnosis of DLB is a progressive and fluctuating cognitive decline with recurrent visual hallucinations, systematized delusions and spontaneous parkinsonian symptoms. Repeated falls, syncope, transient loss of consciousness and neuroleptic sensitivity are also clinically characteristic. In $\mathrm{AD}$, in contrast, the progressive decline of memory is prominent and neuropsychiatric features usually occur in the later stages [7]. Moderate parkinsonian signs can be observed during both AD and DLB evolution [8]. Thus, in some cases, the clinical distinction of patients with DLB from those with $\mathrm{AD}$ may be difficult because of overlapping symptoms such as cognitive decline, psychiatric signs and parkinsonism. When the initial presentation of DLB is characterized by impaired cognition, the disease can mimic AD [5,9].

Differentiation of the two diseases from each other can be achieved by neuropsychological evaluation, which can disclose impaired performance of similar severity in both diseases with regard to attention, frontal lobe function and motor sequencing in DLB and AD [10]. In practice, differential diagnosis by the use of this method is most likely to be realized in specialized centers of neurology and psychiatry. A previous study has shown that noninvasive imaging modalities such as PET or SPECT may be useful methods for the diagnosis of dementing disorders, especially in the differential diagnosis of dementia and depression of the elderly [11]. In another study, it was found that in depression, symmetrically metabolic changes are found in the prefrontal cortex, and these changes improve with treatment [12], which was not typical for dementia.

In $\mathrm{AD}$, the abnormal pattern of regional cerebral blood flow ( $\mathrm{rCBF}$ ) that is characteristic of the disease is bilaterally decreased perfusion in the temporal and parietal regions [13]. However, heterogeneous patterns of rCBF deficits have been seen in $\mathrm{AD}$ on examination with SPECT. This heterogeneity may reflect either different stages of the disease or cognitive subtypes [14]. In DLB, temporoparietal hypoperfusion has been shown to be associated with occipital hypoperfusion, which could explain the visual hallucinations in this illness [15].

The aim of this study was to evaluate FDG-PET brain imaging in assessing clinically manifested DLB by measuring regional glucose metabolism.

\section{Methods}

Five patients ( 5 males, mean age $75 \mathrm{y}$, age range 69-79) with fulfilled clinical criteria for DLB were referred to our department for PET examination. The disease duration was $3 \pm 1 \mathrm{y}$. Every patient underwent a psychological examination including MMSE (mini mental state examination). Magnetic resonance imaging (MRI) of the brain was performed in all the patients. The data gathered from the patients were compared to the PET brain images from a normal data base in our department (six normal subjects, 2 males, 4 females, mean age 63, age range 45-79). The normal subjects had no history of neurological or psychiatric disease. The PET images were obtained 30 minutes after i.v. injection of $150 \mathrm{MBq}$ FDG using a Siemens ECAT-ART (CTI, Knoxville, TN, USA). Attenuation correction of the images was made with an additional transmission scan using two 137-Cs point sources [16]. Reconstruction was performed using the filtered back projection method (FBP) applying a Gaussian filter (FWHM $4.0 \mathrm{~mm}$ ) and a zoom factor of 2.50. An acquisition matrix size of $128 \times 128$ was chosen. Six regions of interest (ROI) were drawn on a $10 \mathrm{~mm}$ thick transaxial brain slice at 4.5 $\mathrm{cm}$ parallel to the cantomeatal line (CML) and two ROIs in the central region, and the SUVs of these regions were measured. Z scores for each patient were calculated according to the formula of Albin et al [17], as follows:

$\mathrm{Z}$ score $=$ (patient regional SUV - controls regional SUV (mean value))/ controls regional SUV standard deviation).

A Z score of $\leq-2$ was considered to be significant.

\section{Results}

Diffuse reduced glucose uptake in the entire cortical region with relative sparing of the central region (Figure 1), but including the occipital cortex was determined in all the patients, which was less remarkable in patient 2 . The mean SUV in the patient group was $3.30 \pm 0.30$ vs. $6.10 \pm$ 0.70 in the normal subjects. The detailed Z-scores of the patients' cerebral metabolic patterns are shown in Table 1. MRI of the brain showed a mild degree of cortical atrophy in three of the patients without further specific pathologic findings.

\section{Discussion}

Postmortem examination remains the only way to definitively confirm the diagnosis of DLB, which is based on evidence of Lewy bodies in the cortex, the subcortical regions (nucleus basalis of Meynert) and the brain stem (substantia nigra and locus coeruleus) $[5,18,19]$. With the promise of neuroprotective treatments, early diagnosis is increasingly important. A more extensive cholinergic deficit has been observed in DLB compared with AD [9]. This observation explains the beneficial effects of cholinergic therapy in DLB (cholinesterase inhibitor), which has been shown to improve impaired cognitive functions [20]. This implies that early diagnosis would greatly improve the effectiveness of the treatment. 


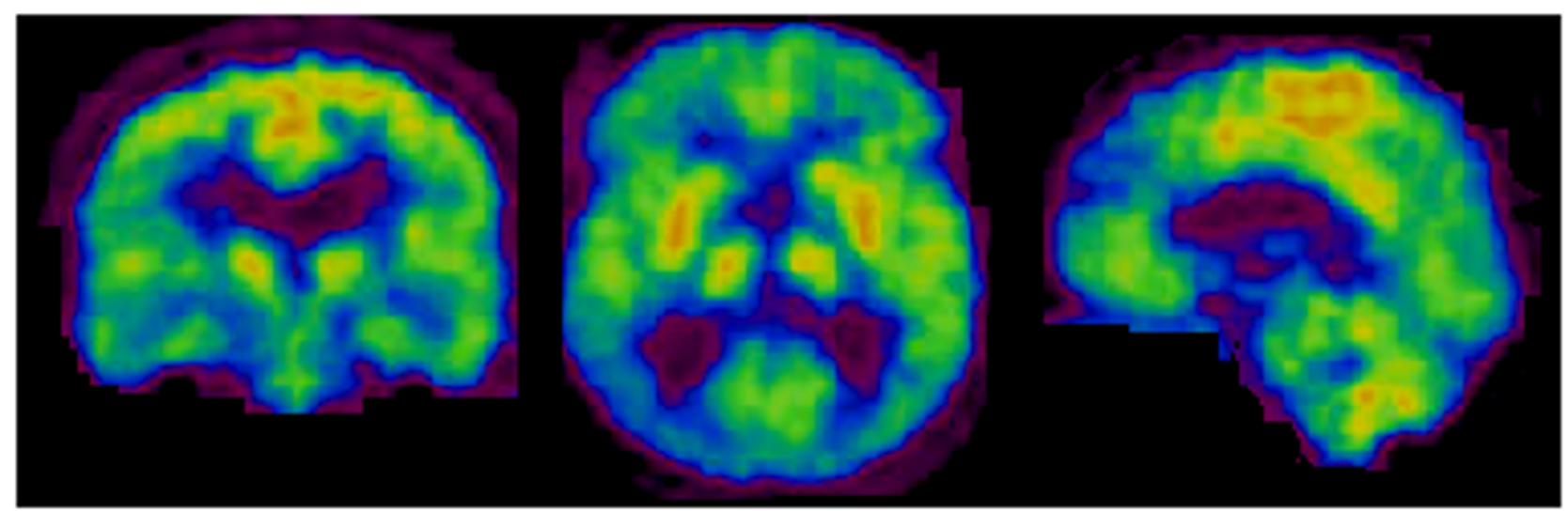

Figure I

m, 75 y, Brain FDG-PET shows a diffuse glucose hypometabolism with relative sparing of the central region

Table I: Z scores of patient regional mean SUV compared to controls

\begin{tabular}{ccccccccc}
\hline Patient Nr. & r.fr. & I.fr. & r.tp. & I.tp. & r.oc. & I.oc. & r.c. & I.c. \\
\hline PI & -2.7 & -3.1 & -3.1 & -3.4 & -3.0 & -3.1 & -1.4 & -2.3 \\
P2 & -1.8 & -2.1 & -2.3 & -2.0 & -2.9 & -3.1 & -1.4 & -0.6 \\
P3 & -2.9 & -3.2 & -2.6 & -3.4 & -2.6 & -2.9 & -1.8 & -1.9 \\
P4 & -2.3 & -2.7 & -2.3 & -3.1 & -2.3 & -2.7 & -1.9 & -1.7 \\
P5 & -2.6 & -3.0 & -2.7 & -3.5 & -2.7 & -3.1 & -2.2 & -2.1 \\
\hline
\end{tabular}

r. = right, $\mathrm{l} .=$ left, fr. $=$ frontal, $\mathrm{pt} .=$ temporoparietal, oc. $=$ occipital, $\mathrm{c} .=$ central

Although clinical criteria have been defined for DLB [3], development of objective measures to confirm clinical findings would be helpful in clinical routine. Recent studies have suggested that functional imaging with dopaminergic presynaptic ligands and postsynaptic $\mathrm{D}_{2}$ receptors like ${ }^{123}$ I-FP-CIT and ${ }^{123}$ I-iodobenzamide help to distinguish DLB from AD, since there are loss of dopaminergic neurons in DLB [21-23]. Another study demonstrated reduced vesicular monoamine transporter type 2 expression in patients with DLB indicating degeneration of nigrostriatal projections [24]. The patients described in this report fulfilled the clinical criteria for DLB. The PET examination revealed that all patients had glucose hypometabolism in the entire cortex with relative sparing of the primary sensory-motor cortex. In addition there was marked hypometabolism in the occipital cortex, which corresponds with results from other studies $[1,25]$. This characteristic pattern of cortical hypometabolism includ- ing the occipital areas could be a result of diaschisis due to disruption of intracortical connections. Diaschisis is defined as depression of regional neuronal metabolism and cerebral blood flow caused by dysfunction in anatomically separate but functionally related neuronal regions [26].

The results in this study were obtained in routine hospital work. We did not measure the arterial input function, as performed by Albin et al, since we consider it too invasive and inconvenient to the patient for routine use.

\section{Conclusion}

With the limitation that occipital hypometabolism may be manifested not only in DLB [27], we propose the use of a combination of FDG-PET and striatal dopamine terminal imaging as a supplement to the clinical examination to establish the final diagnosis of DLB and as the basis for a differentiated therapy. 


\section{Competition interests}

None declared.

\section{Authors' contribution}

SM designed the study, performed the statistical analysis and drafted the manuscript.

PK performed the quality control of the examination procedure.

HK participated in the design of the study.

TB participated in the design of the study and preparation of the manuscript.

All authors read and approved the final manuscript.

\section{References}

I. Byne EJ, Lennox G and Godwin-Austen R Diffuse Lewy body disease: clinical features in 15 cases. J Neurol Neurosurg Psychiatry 1989, 52:709-717

2. Hansen L, Salmon D, Galasko D, Masliah E, Katzman R, DeTeresa R, Thal L, Pay MM, Hofstetter $R$ and Klauber M The Lewy body variant of Alzheimer's disease: a pathological and clinical entity. Neurology 1990, 40:1-8

3. McKeith IG, Galasko D, Kosaka K, Perry EK, Dickson DW, Hansen LA, Salmon DP, Lowe J, Mirra SS, Byrne EJ, Lennox G, Quinn NP, Edwardson JA, Ince PG, Bergeron C, Burns A, Miller BL, Lovestone S, Collerton D, Jansen EN, Ballard C, de Vos RA, Wilcock GK, Jellinger $\mathrm{KA}$ and Perry $\mathrm{RH}$ Consensus guidelines for the clinical and pathologic diagnosis of dementia with Lewy bodies (DLB): report of the consortium on DLB international workshop. Neurology 1996, 47:1113-1124

4. Lewy FH Paralysis agitans. In: Pathologische Anantomie. Handbuch der Neurologie (Edited by: Lewandowsky M) Berlin: Springer Verlag 1912, 920933

5. Hansen LA and Noville RL Lewy body disease. Curr Opin Neurol Neurosurg 1992, 5:889-894

6. Ransmayr G, Wenning GK, Seppi K, Jellinger K and Poewe W Demenz mit Lewy-Körperchen. Nervenarzt 2000, 71:929-935

7. McKhann G, Drachman D, Folstein M, Katzman R, Price D and Stadlan EM Clinical diagnosis of Alzheimer's disease: report of the NINCDS-ADRDA Work Group under the auspices of Department of Health and Human Services Task Force on Alzheimer's disease. Neurology 1984, 34:939-944

8. Soininen H, Laulumaa V, Helkala EL, Hartikainen P and Riekkinen PJ Extrapyramidal signs in Alzheimer's disease: a 3-year followup study. J Neural Transm Park Dis Dement Sect 1992, 4: I07-I I9

9. Foerstl H, Burns A, Luther P, Cairns N and Levy R The Lewy body variant of Alzheimer's disease: clinical and pathological findings. $\mathrm{Br} J$ Psychiatry 1993, I 62:385-392

10. Gnanalingham KK, Byrne EJ, Thornton A, Sambrook MA and Bannister $P$ Motor and cognitive function in Lewy body dementia: comparison with Alzheimer's and Parkinson's diseases. J Neurol Neurosurg Psychiatry 1997, 62:243-252

II. Costa DC, Pilowsky LS and Ell PJ Nuclear Medicine in neurology and psychiatry. Lancet 1999, 354: I I07-I I

12. Goodwin GM Functional imaging, affective disorder and dementia. Br Med Bull 1996, 52:495-5 I2

13. Neary D, Snowden JS, Shields RA, Burjan AWI and Northen B Single photon emission tomography using $99 \mathrm{mTc}$-HMPAO in the investigation of dementia. J Neurol Neurosurg Psychiatry 1987, 50:1101-1109

14. Waldemar G, Bruhn P, Kristensen M, Johnsen A, Paulson OB and Lassen NA Heterogeneity of neocortical cerebral blood flow deficits in dementia of the Alzheimer type: a $99 \mathrm{mTc}-\mathrm{d}, \mathrm{I}$ HMPAO SPECT study. J Neurol Neurosurg Psychiatry 1994, 57:285295

15. Donnemiller E, Heilmann J, Wenning GK, Berger W, Decristoforo C, Moncayo R, Poewe W and Ransmayr G Brain perfusion scintigra- phy with $99 \mathrm{mTc}$-HMPAO or $99 \mathrm{mTC-ECD}$ and $|23|-\beta-$ CIT single-photon emission tomography in dementia of the Alzheimer-type and diffuse Lewy body disease. Eur J Nucl Med 1997, 24:320-325

16. Mirzaei S, Knoll $\mathrm{P}$ and Köhn H Comparison of different methods for attenuation correction in brain PET. Nuklearmedizin 2000 , 39(6): N95

17. Albin RL, Minoshima S, D'Amato CJ, Frey KA, Kuhl DA and Sima AA Fluoro-deoxyglucose positron emission tomography in diffuse Lewy body disease. Neurology 1996, 47:462-466

18. Gibb WR, Luthert PJ, Janota I and Lantos PL Cortical Lewy body dementia: clinical features and classification. J Neurol Neurosurg Psychiatry 1989, 52:185-192

19. Kosaka K, Yoshimura M, lkeda K and Budka H Diffuse type of Lewy disease: progressive dementia with abundant cortical Lewy bodies and senile changes of varying degree - a new disease? Clin Neuropathol 1984, 3:185-192

20. Lebert F, Souliez $L$ and Pasquier $F$ Tacrine and symptomatic treatment in Lewy body dementia. In: Dementia with Lewy bodies. Clinical, Pathological and Treatment Issues (Edited by: Perry R, McKeith I, Perry E) Cambridge: Cambridge University Press 1996, 439-448

21. Walker Z, Costa DC, Ince P, McKeith IG and Katona CLE In-vivo demonstration of dopaminergic degeneration in dementia with Lewy bodies. The Lancet 1999, 354:646-647

22. Walker Z, Costa DC, Livingston G, Walker RW, Jansen A and Katona CL Lewy body dementia: the study of post-synaptic dopaminergic receptors with I23I-IBZM SPET. Eur J Nucl Med 1997, 24:609-614

23. Walker Z, Costa DC, Walker RW, Shaw K, Gacinovic S, Stevens T, Livingston G, Ince P, McKeith IG and Katona CL Differentiation of dementia with Lewy bodies from Alzheimer's disease using a dopaminergic Presynaptic ligand. J Neurol Neurosurg Psychiatry 2002, 73: |34-|40

24. Suzuki M, Desmond TJ, Albin RL and Frey KA Striatal monoaminergic terminals in Lewy body and Alzheimer's dementias. Ann Neurol 2002, 5 1:767-771

25. Minoshima S, Foster NL, Sima AA, Frey KA, Albin RL and Kuhl DE Alzheimer's disease versus dementia with Lewy bodies: cerebral metabolic distinction with autopsy confirmation. Ann Neurol 200I, 50:358-365

26. Brunberg J, Frey K, Horton J and Kuhl Crossed cerebellar diaschisis: occurence and resolution demonstrated with PET during carotid temporary ballon occlusion. AKNR 1992, I 3:5861

27. Levine DN, Lee JM and Fischer CM The visual variant of Alzheimer's disease: a clinicopathologic case study. Neurology 1993, 43:305-313

\section{Pre-publication history}

The pre-publication history for this paper can be accessed here:

http://www.biomedcentral.com/1471-2385/3/1/prepub

Publish with Biomed Central and every scientist can read your work free of charge

"BioMed Central will be the most significant development for disseminating the results of biomedical research in our lifetime. "

Sir Paul Nurse, Cancer Research UK

Your research papers will be:

- available free of charge to the entire biomedical community

- peer reviewed and published immediately upon acceptance

- cited in PubMed and archived on PubMed Central

- yours - you keep the copyright 